\title{
Research on the Education Model of Innovation and Entrepreneurship across the Universities of Jilin Province under the Background of "Double Innovation"
}

\author{
Chunyan Gong \\ College of Humanities and Sciences of Northeast Normal University, Changchun, \\ Jilin Province 130117, China \\ 562499369@qq.com
}

Keywords: "Double Innovation”; Universities of Jilin Province; Education Model

\begin{abstract}
Innovation and entrepreneurship Education is a newly conceptualized notion in education. As an important link in the strategy of innovation-driven development, "double innovation" can not only expand the employment to drive economy forward but contributes to promote the local college to carry out the transformation development, to explore the new talent cultivation model and thus to improve education of innovation and entrepreneurship for college students. Therefore, the paper will take the universities of Jilin Province as research objects to find out the profound reasons that hinder the colleges to develop the education of innovation and creation. As a result, effective countermeasures are explored so as to deepen the education reform and exert the multiplicative effect of the innovation entrepreneurship on the employment to thus help the local colleges contribute more to regional economic development.
\end{abstract}

\section{Introduction}

According to the new theory of innovation and entrepreneurship education, innovation and entrepreneurship form a symbiont circle. Innovation builds the foundation for the entrepreneurship and the entrepreneurship acts as a carrier and manifestation of the innovation. The ability of innovation leads to the success and failure of the entrepreneurship. The innovation and entrepreneurship education covers the connotation of both "innovation education" as well as "entrepreneurship education". Innovation education pays more attention to students" overall plans for their future development with more emphasis on cultivation and development of students' innovation thoughts while entrepreneurship education focus more on students' overall plans to the patterns to realize their self-worth with more emphasis on cultivation of practical ability. Therefore, the innovation and entrepreneurship education is not simply summed up by innovation education and entrepreneurship education but act as a whole to link these two closely. Innovation and entrepreneurship education advocates the school to get themselves within their means, the students to return the subjects and the subjects to return their essence. It also promotes the school to reconstruct their class, transform the function, content as well as the implementing methods of curriculum to put more emphasis on students' participation, independent exploration and practicing.

\section{Basic Situation}

Though many college and universities have just stepped their foot on the road to develop "double innovation" education, they are sparing no effort to promote this education strategy from the spot to the surface with a holistic viewpoint and systematic thinking, showing following trends: firstly, "single innovation" has been transformed into "double innovation". If we say that the "Entrepreneurship" has lightened the passion of education, then transforming "entrepreneurship" to the "Innovation entrepreneurship" is to deepen and improve the overall idea of education and promote the entrepreneurship with innovation or creativity to further promote the updating of education content and model; secondly, the education has reach the stage from small-scale to commonality even to popularity. Innovation and entrepreneurship education was once considered to be the education provided for a minority of students with innovative ideas, which led to small 
education scale.

With less than $2 \%$ business start-up rates among the college students in our country, the success venture enterprises only occupied $10 \%$ in all. Stimulated by the environment of "double innovation education", many school start to shift their attention from the "branch" to "trunk", from "small-scale" to all the students and serve for them in their whole development process; Thirdly, "fragmented" parts have been integrated into an "embedded" whole. Currently, courses set for Innovation and Entrepreneurship Education is relatively fragmented. All these courses come apart with little relation to each other. All local colleges are positively changing their original idea of simple principal and major and introducing "trans-boundary" to promote to foster innovation and entrepreneurship; fourthly, "scenario" simulation has been transformed into "actual battle". Innovation and entrepreneurship education should follow the "Unity of Knowledge and Action" education idea to create the environment docking with the real world of work, provide the actual projects for them to let them organize their own innovation team to finish the project thus to link teaching, learning, practicing and creating tightly and an ecosystem of Innovation and entrepreneurship education to link the theory with the real life and integrate the situation with actual combat.

\section{Analysis of Current Situation and Existing Problems of Innovation and Entrepreneurship Education across Universities of Jilin Province}

Attaching great importance to the work of Innovation and Entrepreneurship Education, the Jilin Government has formed a steering committee for Innovation and Entrepreneurship Education in Jilin Province to promote the construction of System and Mechanism concerning the work of college Innovation and Entrepreneurship education in a coordinated and all-round way. By the end of 2016, curriculum system for college Innovation and Entrepreneurship Education in Jilin Province has gradually been perfected, with 219 compulsory course and 408 elective course. 21 universities have opened their online courses. 769 Teaching laboratories and 703 outside- school Practical Bases have been established. Besides, 126 provincial outside-school practical bases and 80 provincial innovative and venture bases for college students have also been set up. The first "Internet Plus" College Student Business Plan Competition, "Jichuang Cup" College Teaching Contest of Business-guidance Course within the scope of the whole province as well as the third "Dream Cup" College Student Business Plan Competition have all been held in Jilin Province with high quality, which has created a sound environment and atmosphere for innovation and entrepreneurship education in college.

However, College Innovation and Entrepreneurship Education in Jilin Province is still lags far behind that in colleges in other provinces. To get first-hand data with more accuracy, the authors led the other task group members to design the questionnaire to investigate the current situation of college Innovation and Entrepreneurship Education in Jilin Province and visit more than ten colleges across the province to send these questionnaires out. The questionnaire mainly focuses on the most puzzling problems that hinder the college to carry out their Innovation and Entrepreneurship Education. About 200 questionnaires were given out to entrepreneurial teaching staff in different colleges in Jilin Province. 168 effective questionnaires were collected. The statistic results of the feedback from the questionnaires are shown in Fig.1 


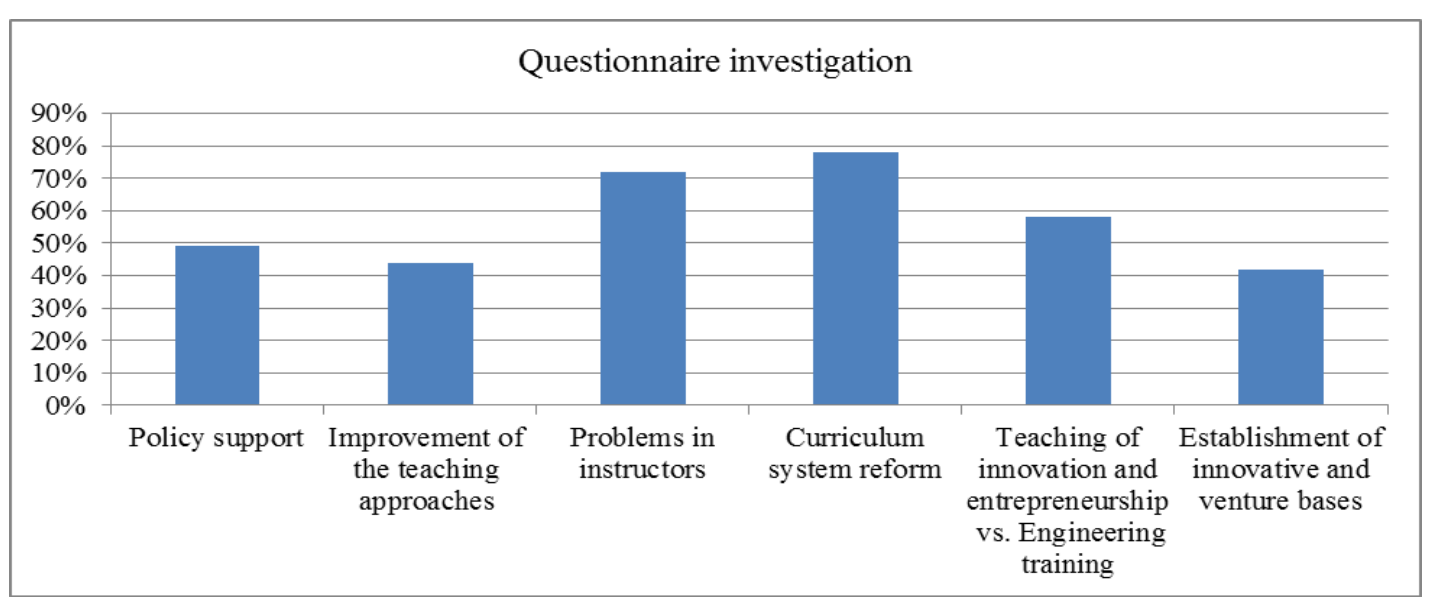

Fig.1 Statistic results of the questionnaires about current situation of college Innovation and Entrepreneurship Education in Jilin Province

Based on the result concluded from the questionnaire, the authors has found several problems existing in the development of Innovation and Entrepreneurship Education in college in Jilin Province.

The "Double Innovation" Education Curriculum Contents are too Unitary and They are not Closely Linked with the Professional Education. According to an uncompleted statistic, more than seventy percent of local colleges have not form their own systematic and independent "Double Innovation" curricula group. There are also some colleges without any entrepreneurship courses for now. Among those college running "double innovation" courses, some colleges set "double innovation" as an elective common course and embed it into "Career Planning Curriculum" as a module with only 4 or 8 class hour; as for some other colleges, though they includes basic entrepreneurship courses in the list of compulsory course, but the "double innovation" course contents are not only unitary but homogenized. "Double innovation" course contents for the economic management major are the same as that for the students study in a totally different field, which make it completely impossible to combine the "double innovation" education with the professional education effectively. The professional education is to impart specialized knowledge of a certain subject systematically thus to help him/her improve the professional skills. Thus, local colleges should integrate Entrepreneurship Education into professional education while developing "double innovation" course, to establish practical "Double Innovation" curriculum system. Classified Teaching Mode should also be carried out as a new approach to deepen the "Double Innovation" Education Reform in College.

"Double Innovation" Education has a Serious Shortage in Teaching Staff and it Cannot Correspond to Practice Teaching. Excellent "double innovation" teaching staff should have not only deep theoretical knowledge, consummate professional skills and effective coaching approach, but rich capabilities to provide business guidance. Current teaching staff's abilities vary at providing "double innovation" education. The main source of these staff can be divided into following three categories. Firstly, The counselors team. Though these counselors are young and energetic so they can communicate with the students in their class, they do not have enough theoretical knowledge and practical experience, thus it would be easy for them to become only the armchair generals. Secondly, professional teachers from economic management major. Though these teachers have rich teaching experience and quite strong management skills, they tend to emphasize more on theory rather than practical part while teaching trans-disciplinary "double innovation" courses. Thirdly, they are outside experts with entrepreneurial experience. The greatest strength of these instructors is that they have rich experience in actual combat so that they enjoy large popularity among the students. But limited by their schedule, in most cases, they can only present their experience by delivering lectures on a regular or irregular basis or in the form of a special subject, to teach the students to combine the theory and the reality. Therefore, all colleges in different regions should pay more attention to the teaching staff team construction and build a 
teaching team with proper echelon and excellent instructors.

Uninformed and Less-Developed "Double Innovation" Education Methods do not Match "Double Innovation" Education Idea. Currently, most of local college adopted traditional enclosed classroom method as the major approach in "double innovation" course teaching and rarely carry out courses to make students experience and participate in the actual combat, which makes it difficult to cultivate their practical ability. During our investigation, we found that four phenomena in colleges as following: Firstly, They tend to take classroom method as the major teaching approach to "spoon-feed" the students. Secondly, though teaching in a small-scale class, teachers still adopt common teaching method. The class is still dominated by the teachers, with little interaction with the students. Thirdly, students do more interaction in experiment in lab, but most of their experiments are monomial and static experiments, lead to lack of practical content, fragmentation, low-level and disconnection in experiment as well as the division of the curriculum and the experiment, thus they cannot be integrated into a whole. 4. Teachers teach a large amount of knowledge and leave the students with so much homework and rules that the students can only follow mechanically so they cannot make any progress in this process. Essentially, all these problems are caused by teachers' lack of creativity in their teaching methods. In this new era and this new context, teachers in charge of these courses in all colleges should ceaselessly study the teaching method to find more creative approaches to teach the students more effectively.

"Double Innovation" Education Evaluation System is Imperfect and it did not Cooperate Well with the Teaching Effect Monitoring System. "Double innovation" education evaluation system is a quite important part in Entrepreneurship Education. It has been set on Basic requirements for Entrepreneurship Education in Regular University that the universities should combine with the actual condition of the school, take the entrepreneurship education teaching effect as an important content to evaluate the undergraduate teaching and one important index to measure the quality of talent training to strengthen self-evaluation and self-inspection and show the result on the annual reports of undergraduate teaching quality to accept the supervision of the whole society. Though the government has announces the policy, because the development of "double innovation" education in different colleges is uneven, and the nation have not determined the classification and rating standard to define research university, local universities and higher vocational college, more than half colleges and universities have not finished built "double innovation" education evaluation system. Even they have built up the system, there were still a lot to improve. Moreover, quite a lot of schools have not formed the leading group to specialize in development of "double innovation". In most schools, the teaching tasks of "double innovation" are always given by schools' educational administration or the Employment Center to the teaching units, which then will implement the task. The "double innovation" education teaching effect evaluation is almost out of control. Thus, colleges in Jilin Province should take the time to build and perfect "double innovation" education teaching effect system and timely monitor the teaching sections and ensure the effectiveness of "double innovation" education.

\section{Countermeasures for College in Jilin Province to build pattern of Innovation and Entrepreneurship Education}

Adopt "Three Combinations" to Position the Goal of "Double Innovation" Education. Whether the goal positioning is scientific and proper or not directly determines the quality of talent cultivation. The "three combinations" look deep into the goal positioning of "double innovation" education from perspective of nation, region and the schools. Firstly, to combine the requirement of the country's policy to carry out the innovation of competence education. Essentially, "double innovation" education is the competence education. It requires "the high education to pay more attention to cultivate college students' ability of innovation and practice as well as to foster entrepreneurialism to thus to improve their humanistic quality and scientific quality." Colleges in different area should change their original "employment-oriented" target to "Entrepreneurship-oriented" target and cultivate them to be person with strong entrepreneurial consciousness, positive attitude towards innovation as well as excellent capability of 
entrepreneurship. Secondly, combine with the need of regional economic development to carry out innovation of ability education. The strategy theme has been proposed in the Outline of the National Medium-and Long-term Program for Education Reform and Development that "Education should focus on the capability cultivation, optimize the knowledge structure, enrich students' social practice activities to enhance capability-building. Colleges in different regions shoulder to undertake to develop regional economies, they should transform their original enclosed running style into open style, to cooperate with local enterprises with jobs matches with school's major and jointly develop Innovation and entrepreneurship training. Thirdly, combine with the self advantages of the school to carry out the innovation of individual education. Colleges should change their original education idea of "school standard" to "students standard" to fully respect students" individualized needs, based on which existing advantageous resources of the school could be gathered to build up the platform for students' diversified development. The college should cultivate the students' characters of Innovation entrepreneurship by all means and seek to develop together with the students.

Design "Double Innovation" Education Curriculum System Based on the Content in and out of Class. Colleges in different areas should design multi-level three-dimensional "double innovation" Curriculum system according to talent cultivation goal, scale and quality requirements of innovation and Entrepreneurship education. Firstly, design teaching system targeted for different audience. Lessons can be given according to different phase, audience with different level. Phased approach can be divided into three parts including the theory and practice part, holistic cognition, practice operation and practical application. Differential Object design means to make different teaching material for different audience based on theirs different needs in proficiency in the knowledge and different requirements of the practice. Multi-level teaching method is to divide the teaching process in order of the difficulty, into two parts: the perceptual cognition part and the rational exploration part. Secondly, build a multiple teaching resource sharing system. Innovation and Entrepreneurship Education should stand on the front line of in this Information age of "Internet Plus". Therefore, colleges should make full use of modern multimedia and internet technology to build up an autonomous, open and interactive multiple teaching resources sharing system, as shown in Fig.3-1, to better serve multi-level students and cover the entire teaching process.

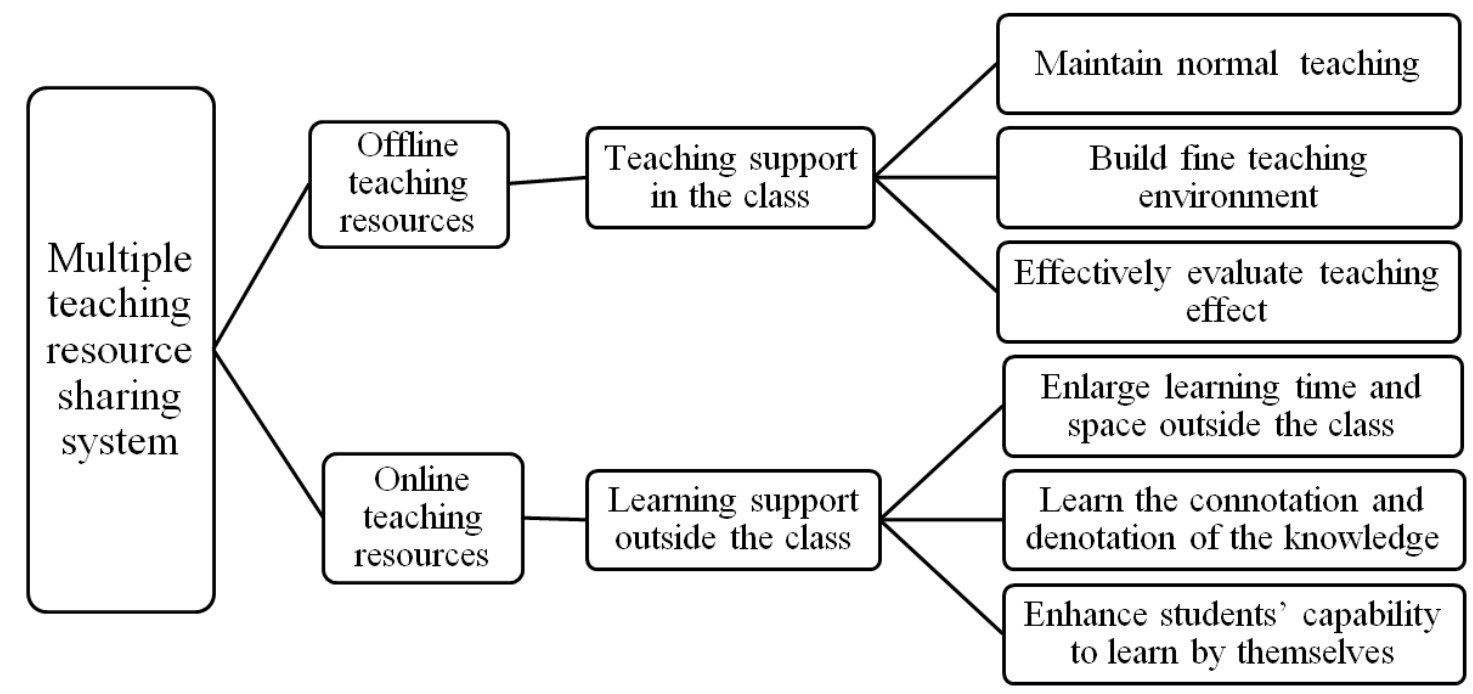

Fig.2 Sharing system of multiple teaching resource

Build "Double Innovation" Teaching Team based on "Three Improvements". According to incomplete statistics, national student-teaching staff ratio in the field of double innovation education is about 2000. Firstly the number is even higher in some less developed areas. A group of good teaching staff is the key for colleges to effectively develop Innovation and Entrepreneurship Education. Thus, colleges should focus on "three improvements" to build a "double innovation" teaching team quickly and effectively. Firstly, improve of teaching ability. Colleges should make 
phased multi-level internal and external training plans to lead teachers to take initials to deeply learn the knowledge of multiple subjects that can help to improve the teaching effect including "double innovation" management theory, management, economics, psychology. Secondly, improvement of scientific research capacity. Colleges should encourage teachers to build "double innovation" education projects to make the profession more interactive with "double innovation" to achieve "research-teaching integration". Thirdly, improvement of practice capability. Emphasis on practice part is the most conspicuous feature of Entrepreneurship Education that differ it from other discipline. There are fewer "double innovation" teaching staff in colleges who can effectively combine the theory with the practice. Given this situation, colleges should take more attention to cultivate "double innovation" teachers, let those less experienced entrepreneurial teachers to go into enterprises to do some homework, let them work with the enterprises to design and develop entrepreneurship project jointly. Moreover, colleges should also guide these teachers to obtain corresponding professional certificates to be competent "double innovation" teacher as soon as possible.

Attract the Resources from Many Parties to Establish the Coordinative Mechanism to Cultivate Innovation Talents. Multi-party Collaboration means collaboration between school and school, school and enterprises, school and region, school and research institute and so on. With multi-party collaboration, the school can seek after the goals of talent training and enterprise incubating by integrating resources from multi parties including the school itself, the enterprises, research institute, industry association, the governments, angle investment alliance, investment fund and so on to build an platform for colleges to cooperate and share resource, the platform that can provide students who engage in innovation and entrepreneurship with support related research site ,tutor support, investments and consultants. Through multi-party collaboration, the college can accelerate its speed to develop innovative entrepreneurial culture.

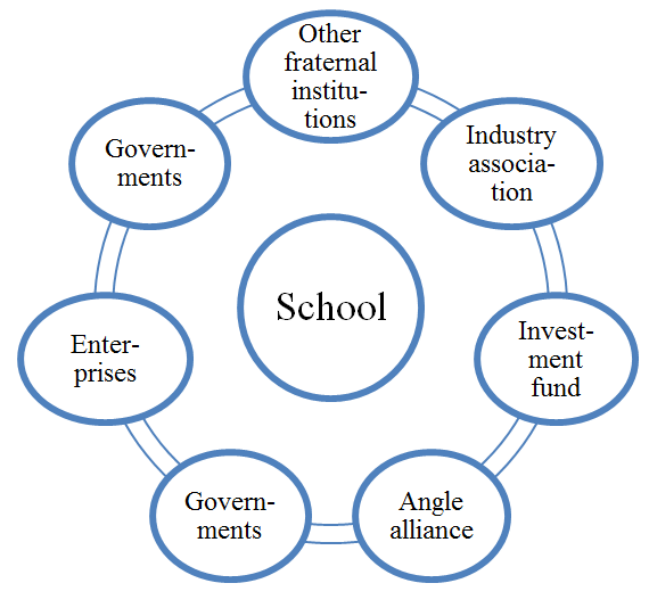

Fig.3 multi- party coordinative mechanism to cultivate innovation talents

\section{Focus on "Three Links" to Perfect "Double Innovation" Education Evaluation System.}

Perfect Entrepreneurship education evaluation system can constantly improve the education quality and connotation. By focusing on "three links", it means as follows. Firstly, focus on "double innovation" teaching effect. This link mainly evaluates the hardware and software condition to develop "double innovation" education. Software condition mainly includes the design of "double innovation" curriculum system, the construction of "double innovation" teaching team, all kind of Innovation and Entrepreneurship competences for the students and so on. Hardware condition refers to the equipment and utilization of campus labs as well as the development and utilization of out-of-school practice base. Secondly, focus on effect to train "double innovation" talents. This link relates the final purpose of Entrepreneurship Education. The emphasis should be taken on the Whole-Process Follow-up of the students development from their grades at school, their internship performance outside the school and their career development after graduation. Since this requires a lot of works, the college should cooperate with a common effort to achieve the goals. Thirdly, focus on "double innovation" project benefit. The colleges should evaluate students' Entrepreneurship 
Project from several aspects including the project commercialization, the growth and the profitability. Schools should actively hold entrepreneurship competences that match students' major to provide the students with platform to practice their ability.

In conclusion, colleges in Jilin Province should take the longer view to integrate resources and power to take effective actions to adjust to the new situations and new demands to be geared to the needs of all-member, of the whole-process, of the talent training and of the future, to make solid progress in innovation and entrepreneurship education reform.

\section{Summary}

The objective of this paper is to provide countermeasures for colleges of Jilin Province to build Innovation and Entrepreneurship Education model. In order to analyze current situation and existing problems of Innovation and Entrepreneurship Education, the main methods of questionnaires and field research are applied. The main findings are that present "Double innovation" education system is imperfect, for the curriculum contents, practical teaching methodology and concept, and evaluation system do not match the requirement of innovative education model. As a result, a new designed model and countermeasures are recommended as to establish a transitional differentiated way among colleges and cultivate more excellent innovative and entrepreneurial talents to contribute the regional economic development.

\section{Acknowledgments}

The paper is the periodically research productions of higher education project of Jilin higher education association in 2016 "A study on the deepening innovation and entrepreneurship education in colleges and universities in Jilin Province in era of double innovation"(Project No: JGJX2016)

\section{References}

[1] Tan Qinghua, Research on the construction of teaching staff of innovative enterprise education in Applied Undergraduate Universities,J of Journal of Baise University,2017,No 1,p130-132.

[2] Zhang Yingying, Lile, ZhangFuli, Analysis on the problems and solutions of innovation and entrepreneurship education in Colleges and universities in China, $\mathbf{J}$ of Innovation entrepreneurship, 2016, No6,p60-64.

[3] Gao Zhigang, Zhan yan, Wang Gang, On the construction of innovation and entrepreneurship education curriculum system in Colleges and Universities, $\mathbf{J}$ of Heilongjiang Researches on Higher Education,2016,No3,p93-95.

[4] Gao Wenbing, The innovation and entrepreneurship education in Chinese Universities under the background of mass entrepreneurship, $J$ of Higher education research in China,2016,No 1.p49-50.

[5] Song Xiujuan, Research on the construction of ecological system of innovation and entrepreneurship education in Colleges and Universities, J of value engineering,2016,p232-234

[6] Tang Li, Reflections on the construction of innovation and entrepreneurship curriculum system for Higher Vocational College Students, J of value engineering,2016,p252-253.

[7] HuangHaina, Wei Guoqiang, The dilemma and effective solution of innovation and entrepreneurship education in local colleges and Universities, J of Journal of Kaifeng institute of education.2016, No 10,p107-108.

[8] Cai Zhaoquan,HuSong, A study on the collaborative mechanism of talents training in Local Universities, J of Journal of Huizhou University.2015,No 1,p94-97.

[9] Xiao Huaiyun, The cultivation of teachers' practical ability in the application oriented Colleges, J of Logistics technology,2015,No 2,p64-66.

[10] Yang Suyun. Analysis of the influence of local humanistic spirit on the innovation and entrepreneurship education in Local Colleges, J of vocational education,2016,No18,p158-159. 